\title{
Applied Strategy Using Reflectors to Improve Electricity Generation of Photovoltaic Panels on Buildings
}

\author{
Khalid Osman Abdulkadir ${ }^{1}$, Moon Keun Kim²* \\ ${ }^{1}$ Department of Electrical \& Electronic Engineering, Xi' an Jiaotong - Liverpool University, Suzhou \\ 215123, China \\ ${ }^{2}$ Department of Architecture, Xi'an Jiaotong - Liverpool University, Suzhou 215123, China \\ *email:Moon.Kim@xjtlu.edu.cn
}

\begin{abstract}
This paper analyses the possibility using a reflector of to improve the solar power output on buildings. Polished aluminium was selected as the most practical reflective material to be integrated on buildings due to various properties including relatively high albedo level, corrosion resistance and thermal conductivity. The material was simulated at optimized angles with respect to the sized Photovoltaic (PV) array while also putting the location under considerations. This strategy provides an annual average of $34.86 \%$ escalation in irradiation and resulted in an increase in power output by $53 \%$ for the PV panels. The relative space saving was evaluated to be $34.65 \%$.
\end{abstract}

\section{Introduction}

As the world population continues to expand, our reliance on energy is proportionally increasing and harnessing energy to maintain our basic standard of living in our buildings. And it is becoming more and more challenging (Lynn, 2010; Chen, 2011). Further, we have to ensure that we are producing energy in a clean and sustainable manner. In the 21st Century, Solar Energy has been the forefront candidate as a source of clean Energy especially as we are becoming increasingly capable of improving the power output efficiency while simultaneously reducing cost of production (Lynn, 2010; Mackay, 2015). Solar panels are also easily accessible as they can be directly mounted in buildings and not necessarily in remote areas such as other power plants (Chen, 2011; Lasnir and Ang, 1990).

Photovoltaic (PV) cells is what is employed for converting the solar irradiance into electricity by utilizing semi-conductors such as Silicon. Solar Irradiance is the power per unit area received from the sun in the form of radiation (Goswami, 2015). Photovoltaic panels increase their power output in direct proportionality to irradiance and inversely to temperature (Lasnir and Ang, 1990).

However, extracting solar energy can be challenging as the earths position relative to the sun is continuously shifting as we move from day to night and as we navigate through the seasons in one calendar year (Mackay, 2015). Furthermore, due to the tilt of our globe on its axis, regions that are located north or south to the equator do not obtain high irradiance from the sun compared to regions positioned near the equator (Chen, 2011).
A PV panel placed for example on the roof of a building receives three types of radiation from the sun; direct beam that was able to make it directly from the sun, diffused radiation that has been refracted by the clouds and finally, reflected radiation which collides any surrounding surface and further reflects back to the panels (DGS, 2013). In this paper we will focus on the latter type of radiation.

According to studies, each material has a specific Reflective radiation index (or Albedo Value, A) (Crawley 2016). This value is 1 for fully reflective materials and 0 for fully absorbing materials. Note that a black tarmac and a snow covered ground have an albedo value of $\sim 0.1$ and 0.6 respectively (World of Physics).

$$
\mathrm{A}=\frac{\text { Reflected Power }}{\text { Incident } \text { Power }}
$$

The initial objective of this research is to find reflective material that is practical to mount on buildings based on a specific set of criteria.

The other and main objective is to strategically place the reflector at an angle with respect to the PV panels in order to obtain better irradiance from the sunlight and this will consecutively increase the power output efficiency. The new power output will finally be compared to conventional PV panels without reflectors.

Due to the low irradiance level of countries located north of the equator; we will be looking at buildings specifically in Calgary, Canada as our subject of research. It is also important to re-mention that extracted power output of PV panels is inversely proportional to temperature and colder countries with a low ambient temperature will have an advantage as the reflectors will cause an increase in the temperature of the panels (Arlas et al, 2015).

\section{Methods}

The initial step was to properly setup the conventional PV panels, as the main research and analysis is to be implemented based on their simulated position. The PV sizing process will further depend on the geographical location of the PV panels. Another deciding factor will be the season, and whether we are considering the summer or winter solstice, as the suns positions over the sky will vary depending on the time of year. The next step is to identify the power consumption in order to standardize the analysis. For this purpose, the consumption of an average Calgary home was considered. Reflective material selection was based on a weighted set of criteria. The most weight was undoubtedly given to the reflectivity of the material, however due to this research also putting 
into consideration the applied nature of the reflectors, other weighted criteria that can envelope practicality were introduced and the final choice was made on a cumulative value of these set conditions. The positioning of the reflector was based on the daily motion of the sun (East to West). The size of the reflector also put into consideration the angle of the incident and reflected rays. The additional radiation was calculated by utilizing the equation for Reflected Radiation on Tilted surface which took into consideration: Tilt Angle of Panel, Tilt angle of mirror, Average Daily Global Radiation and Albedo level of Reflector. The new irradiation value on the panels was used to calculate the new power output of the panels. Finally, space saving was also calculated based on the new number of PV panels that were achieving the initial required power output.

\section{Simulation and analysis}

For the setup of the PV panels the geographical location of Calgary Canada, was identified as follows:

\section{Latitude: $51^{\circ}$ North \\ Longitude: $52^{\circ}$ West}

Further two specific orientations were considered:

Azimuth - Compass angle of the Sun as it moves from East to West over the course of the day (True South $=0^{\circ}$ ).

Zenith - This is the angle of the sun looking up from ground level at the horizon. This angle varies throughout a calendar year.

Initially considering the azimuth and due to the fact that our subject location is in the northern hemisphere the panels will be facing towards the south and towards the equator. Further based on the Zenith, the National Aeronautics and Space Administration (NASA) Meteorology Database (NASA, 2018) was utilized to obtain the perpendicular alignment of the sun with the PV panel in the varying solstice. For the sizing of the PV panels, parameters was based on the average household in Calgary, Canada, with a Home Size of $185 \mathrm{~m}^{2}, 4$ Occupants and $20 \mathrm{kWh}$ Consumption per day.

Longi PV Panels were selected for this research, with the below specifications:

$$
\begin{array}{ll}
\text { Power } & =350 \mathrm{~W} \\
\text { Impp } & =9.16 \mathrm{~A} \\
\text { Vmpp } & =38.2 \mathrm{~V} \\
\text { Efficiency } & =17 \% \\
\text { Area } & =1.9 \mathrm{~m}^{2}
\end{array}
$$

Irradiance Level and average Temperature for all the months was considered (NASA, 2018).

The $P_{p v}$ array watt peak is further calculated using the below equation (DGS, 2013).

$$
\begin{gathered}
P_{p v}\left(W_{p}\right)=\frac{\text { Daily Power Consumption }}{Z_{1} \times Z_{2} \times V_{T}} \\
\text { where, } \\
P_{p v}=\text { PV Array, Watt Peak } \\
Z_{1}=\text { Radiation at Optimum Angle }
\end{gathered}
$$

$$
\begin{gathered}
Z_{2}=\text { Temperature Correction Factor } \\
\qquad \begin{array}{c}
V_{T}=V_{L} \times V_{A} \times V_{u} \\
V_{T}=\text { Overall Loss } \\
V_{L}=\text { Cable Losses }
\end{array}
\end{gathered}
$$

$$
\begin{gathered}
V_{A}=\text { Mismatching Losses (e.g. Lack of MPPT) } \\
V_{U}=\text { Conversion Losses (e.g. From Battery) }
\end{gathered}
$$

In order to identify the number of PV panels required for mounting, the Total Watt Peak of the array is divided by the rated output of the PV panels.

$$
\begin{gathered}
\text { Number of PV Panels Req. } \\
\frac{\text { TOTALW } W \text { Rating }}{\text { Rated Output Watt Peak of PV Panels }}
\end{gathered}
$$

Further the space required for mounting can be calculated by (Fox, 2010):

$$
\begin{gathered}
\text { Space Required }= \\
(\text { Number of PV Panels })(\text { Area of } 1 \text { PV Panel })
\end{gathered}
$$

Reflective material selection was based on a weighted set of criteria. The set of criteria in an order of highest weightage factor were as follows:

Table 1: Reflective material weightage factor

\begin{tabular}{|c|c|}
\hline Criteria & Weight \\
\hline Albedo & 10 \\
\hline Density (Weight) & 9 \\
\hline Fragility & 9 \\
\hline $\begin{array}{c}\text { Corrosion } \\
\text { Resistance }\end{array}$ & 9 \\
\hline $\begin{array}{c}\text { Thermal } \\
\text { Conductivity }\end{array}$ & 8 \\
\hline
\end{tabular}

Optimum Reflector Position and Size

The positioning of the reflectors was based on the daily motion of the sun (East to West) and due to the static nature of the reflector, optimal facing position was south.

Further, in specular reflection, the reflected ray has the same angle to the normal as the incident ray (Fox, 2010).

The angle at which the rays will hit the reflector can be maximized by increasing the reflector material size. However, for practicality, the size of the reflector is recommended to be max. $1.5 \mathrm{x}$ the size of the panel.

Optimum Reflector Angle

To analyse the Reflected Radiation on a Tilted surface and to calculate the optimum angle of the reflector with respect to the PV panel, the below equation was applied (Khorasanizadeh et al, 2013).

$$
\begin{gathered}
H_{R, \text { Reflector }}= \\
H_{g} R_{d, \text { refl. }} \rho_{m} \frac{(1-\cos (\alpha+\beta))}{2} \\
R_{d}=\frac{(1+\cos (\alpha))}{2}(6)
\end{gathered}
$$

where, $\rho_{m}=$ Reflectivity of Reflector

$\beta=$ Tilt Angle of Panel (to horizontal)

$\alpha=$ Tilt angle of Reflector (to horizontal) 
$\mathrm{Hg}=$ Average Daily Global Radiation

The total radiation on the PV Panel with and without reflector is further considered with eq. (7) and (8) (Mackay, 2015, Chen, 2011, Khorasanizadeh et al, 2013, Vidanalage, 2016)

$$
\begin{gathered}
H_{\text {Total }}=H_{\text {Direct }}+H_{\text {Diffused }}, \quad(7) \\
H_{\text {Total }}=H_{\text {Direct }}+H_{\text {Diffused }}+H_{R, \text { reflector }}
\end{gathered}
$$

The new power output is calculated by utilizing the below equation along with the new irradiation level and compared to the initial power output.

$$
\begin{gathered}
\text { New Power Output }=(\# \text { panels }) \times\left(W_{p} \text { Panel }\right) \times \\
\frac{\text { hours }}{\text { day }}\left(\text { equivalent to } 1000 \frac{\mathrm{KWh}}{\mathrm{m}^{2}}\right) \times \\
(\text { Temp. Correction Factor }) \times(\text { Total Loss Factor })
\end{gathered}
$$

And finally the space saving is computed by using equation (10) (Mackay, 2015, Chen, 2011, Callister and Rethwisch, 2011):

$($ Space Saving $)=($ Area of Longi PV Panel $) \times$ (Equivalent number of panels of the power saved)

\section{Results}

Three reflective materials were ultimately chosen as candidates for comparison; 'glass mirror', 'polished aluminium' and 'reflector coated Polytetrafluoroethylene (PTFE)'. The below tables (2-4), show the evaluated results for these three reflective materials (Callister and Rethwisch, 2011; Jorgensen, 1994).

Evaluating the first material, glass mirror, and analysing table 2, very high specular albedo level is observed. Further analysis show its density and weight is also quite favourable. However, it's drastically fragile and has a low thermal conductivity.

Table 3: Material evaluation, Glass mirror

\begin{tabular}{|c|c|c|c|}
\hline Criteria & $\begin{array}{c}\text { Max. } \\
\text { Weight }\end{array}$ & Glass Mirror & Weight \\
\hline Albedo & 10 & $\begin{array}{c}0.72-0.85 \\
\text { (Specular) }\end{array}$ & 8.5 \\
\hline $\begin{array}{c}\text { Density } \\
\text { (weight) }\end{array}$ & 9 & $2500 \mathrm{~kg} / \mathrm{m}^{\wedge} 3$ & 8 \\
\hline Fragility & 9 & High & 2 \\
\hline $\begin{array}{c}\text { Corrosion } \\
\text { Resistance }\end{array}$ & 9 & High & 8 \\
\hline $\begin{array}{c}\text { Thermal } \\
\text { Conductivity }\end{array}$ & 8 & $1.7 \mathrm{~W} / \mathrm{m} . \mathrm{K}$ & 4 \\
\hline Total & 45 & & 30.5 \\
\hline
\end{tabular}

Further assessing, the second material candidate, polished aluminium (table 3 ), we see that it has a reasonable high albedo level, and a slightly higher density. However, it has a very low fragility, high corrosion resistance and extremely high thermal conductivity.

Table 2: Material evaluation, polished aluminium

\begin{tabular}{|c|c|c|c|}
\hline Criteria & $\begin{array}{c}\text { Max. } \\
\text { Weight }\end{array}$ & $\begin{array}{c}\text { Polished } \\
\text { Aluminum }\end{array}$ & Weight \\
\hline Albedo & 10 & $\begin{array}{c}0.65-0.75 \\
\text { (Specular) }\end{array}$ & 7.5 \\
\hline $\begin{array}{c}\text { Density } \\
\text { (Weight) }\end{array}$ & 9 & $2770 \mathrm{~kg} / \mathrm{m} 3$ & 7 \\
\hline Fragility & 9 & Low & 9 \\
\hline $\begin{array}{c}\text { Corrosion } \\
\text { Resistance }\end{array}$ & 9 & High & 8 \\
\hline $\begin{array}{c}\text { Thermal } \\
\text { Conductivity }\end{array}$ & 8 & $39 \mathrm{~W} / \mathrm{m} . \mathrm{K}$ & 7 \\
\hline Total & 45 & & 38.5 \\
\hline
\end{tabular}

Gauging the last contender, reflector coated PTFE (table 4), superiority in all criteria is observed, however it lacks significantly in one specific departments which is thermal conductivity which is a very important factor as we are dealing with the sun and heat.

Comparing the total criteria weight of all three materials, the polished aluminium had the best overall result while putting all the conditions into consideration and making it ultimately the best candidate for integrating reflectors to the building mounted PV panels.

Table 4: Material evaluation: reflector coated Teflon

\begin{tabular}{|c|c|c|c|}
\hline Criteria & Max. & Reflector & Weight \\
\hline Albedo & 10 & 0.8 (Specular) & 8 \\
\hline $\begin{array}{c}\text { Density } \\
\text { (Weight) }\end{array}$ & 9 & $2170 \mathrm{~kg} / \mathrm{m}^{\wedge} 3$ & 9 \\
\hline Fragility & 9 & Low & 9 \\
\hline $\begin{array}{c}\text { Corrosion } \\
\text { Resistance }\end{array}$ & 9 & High & 8 \\
\hline $\begin{array}{c}\text { Thermal } \\
\text { Conductivity }\end{array}$ & 8 & $0.2 \mathrm{~W} / \mathrm{m} . \mathrm{K}$ & 2 \\
\hline Total & 45 & & 36 \\
\hline
\end{tabular}

Reflector Optimum Angle:

In order to select the optimum position for the reflective material, MATLAB was used to compute the results from $1-180^{\circ}$ with the below equation to obtain the maximum 
irradiance angle. Figure 1 shows schematic of PV array with integrated reflector.

$$
\begin{aligned}
& H_{R, \text { Reflector }}=5.9 \mathrm{MJ} / \\
& m^{2} \frac{(1+\cos (\alpha))}{2}(0.75) \frac{\left(1-\cos \left(\alpha+63^{\circ}\right)\right)}{2}
\end{aligned}
$$

Accordingly the maximum radiation was achieved at an angle of $\alpha=44^{\circ}$, with the below increased reflected radiation value.

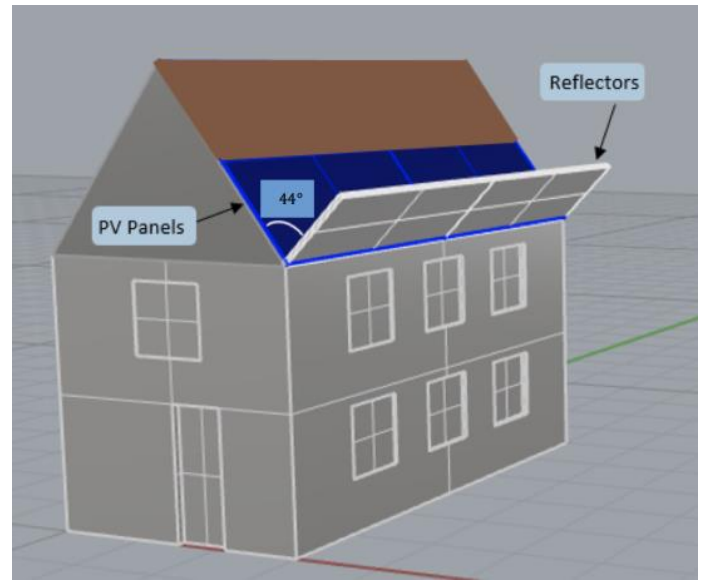

Figure 1: Schematic of PV Array with integrated reflector

Comparison of total irradiation on the panel is further made with and without reflector.

Figure 2 and 3 show the performance of PV system with or without reflectors in the yearly environmental condition, at Calgary in Canada. This study assumed that required solar power generation from PV panel is $20 \mathrm{~kW}$ in a residential building.

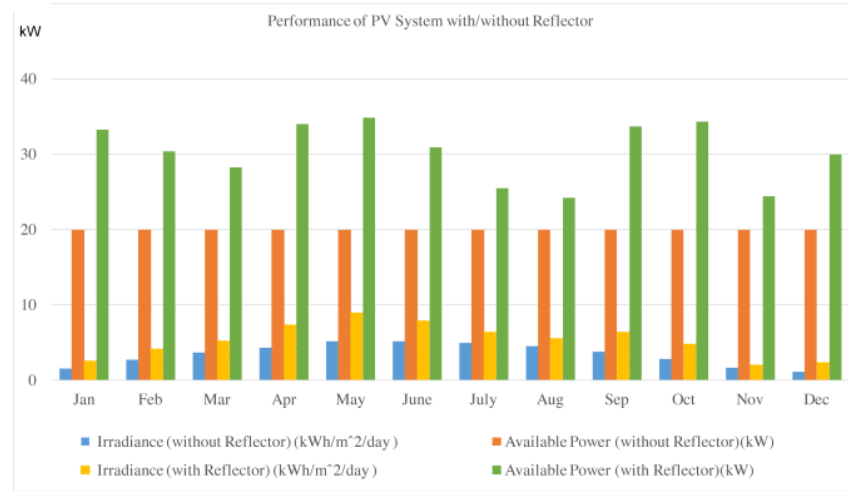

Figure 2: Performance of PV system with/without reflectors

This study calculated actual PV panel size $\left(\mathrm{m}^{2}\right)$ to generate the solar power, $20 \mathrm{~kW}$ for a single residential building based on annual solar radiation. And this study also analyses the PV performance in a building where located in Calgary in Canada as a case study. Annual Calgary weather presents sunny summer season but cold, snowy and long winter season. solar radiation quantity in winter season is quite limited to generate electricity by using PV panel. Therefore, in winter season, much larger PV panel size is necessary to generate the solar power of $20 \mathrm{~kW}$. However, PV reflectors can contribute to minimize the PV panel size because the reflectors added help to generate more electricity.

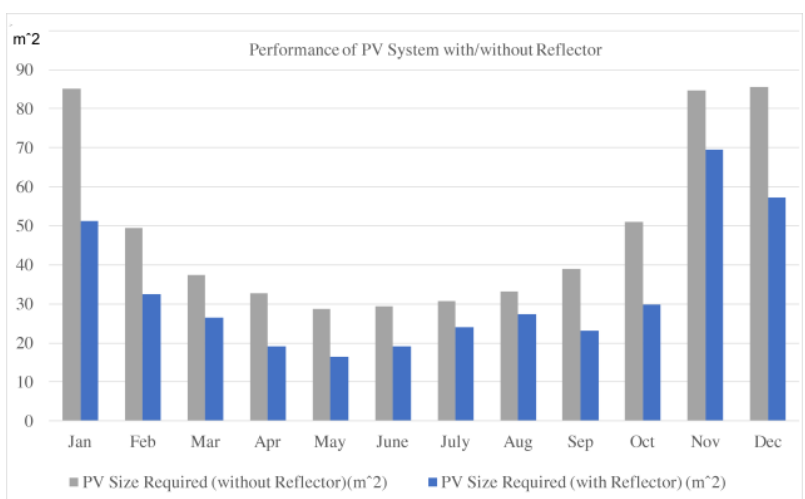

Figure 3: Performance of PV size required with/without reflector

Annual Calgary weather presents sunny summer season but cold, snowy and long winter season. solar radiation quantity in winter season is quite limited to generate electricity by using PV panel. Therefore, in winter season, much larger PV panel size is necessary to generate the solar power of $20 \mathrm{~kW}$. However, PV reflectors can contribute to minimize the PV panel size because the reflectors added help to generate more electricity. Reflectors can increase solar radiation, kwh around $53 \%$ and has impact on increasing PV panel size around 34.65 $\%$. The reflectors price is relatively cheaper than PV panel, and the reflectors can be used as a shading windows in summer season, thus adding reflector has much more economical benefit compared to installation of PV panel additionally.

\section{Conclusion}

Based on a weighted set of criteria, polished Aluminium was identified as the finest reflective material with a reasonable albedo level and practical set of properties for mounting on buildings. Further with the introduction of strategically placed polished aluminium around PV panels located in regions with low irradiance levels such as Calgary, Canada, we saw an annual average increase in Irradiance of $53 \%$. This further translated in an increase in Power output of $34 \%$. Due to less panels required for providing the same output, there was space saving of up to $34.65 \%$. This could further be utilized to add more panels and more clean power, or otherwise could be an added advantage for buildings with space limitations. Reflectors, overall were a valuable addition to the PV System, allowing buildings to produce and consume more clean energy.

\section{References}

Arias, H., Cabrera, J., Hernandez, J. (2015). Performance evaluation of a mono-crystalline PV module cooled by a flat plate solar collector in thermosyphon mode. IEEE $42^{\text {nd }}$ Photovotaic Specialist Conference (PVSC). 1-5 Jun. 
Callister Jr., W.D., Rethwisch, D.G. (9 $9^{\text {th }}$ edition) (2015). Materials science and engineering. Wiley. New Jersey. (USA).

Chen, C.J. ( $1^{\text {st }}$ edition) (2011). Physics of Solar Energy. John Wiley \& Sons, Inc. (USA)

Crawley, G.M. (2016). Solar Energy. World Scientific Publishing Co.

DGS-Deutsche Geselischaft fur Sonnenenergie. (2013). Planning and Installing Photovaotaic Systems: A Guide for Installers. Architects and Engineers. Routledge. New York. (USA).

Fox, M. (2 $2^{\text {nd }}$ edition). (2010). Optical Properties of Solids. Oxford University Press. New York. (USA)

Goswami, D. Y. ( $3^{\text {rd }}$ edition). (2015). Principles of Solar Engineering. CRC Press. Boca Raton (USA).

Jorgensen, G., Willams, T., Wendelin, T. (1994). Advanced reflector materials for solar concentrators. $7^{\text {th }}$ International Symposium on Solar Thermal Conctrating Technologies. National Renewable Energy Laboratory. Moscow. (Russia) 26-30 September 1994.

Khorasanizadeh, H., Mohammadi, K., Mostafaeipour, A. (2013). Establishing a diffuse solar radiation model for determining the optimum tilt angle of solar surfaces in Tabass, Iran. Energy Conversion \& Management. 78, 805-814.

Lasnier, F., Ang, T.G. ( $3^{\text {rd }}$ edition) (1990). Photovoltaic Engineering Handbook. CRC Press. Boca Raton (USA).

Lynn, P. (2010). Eletricity from sunlight. An introduction to photovoltaics. John Wiley \& Sons Ltd. England

Mackay. M.E. (2011). Solar Energy: An Introduction. OXFORD University Press. New York (USA).

NASA (2018), national aeronautics and space administration, surface metheorology and solar energy, https://data.nasa.gov/Earth-Science/SurfaceMeteorology-and-Solar-Energy/wn3p-qsan

Vidanalage, I. (2016). Tilt angle optimization for maximum solar power generation of a solar power plant with mirrors. 2016 IEEE Electrical Power and Energy Conference (EPEC). 1-5 Oct.

World of Physics. Eric Wisstein's. Available: http://scienceworld.wolfram.com/physics/Albedo.ht $\mathrm{ml}$ 